\title{
Current situation and countermeasures of port logistics park information construction
}

\author{
Zhen $\mathrm{Liu}^{1}$, Ya Li ${ }^{2}$, Wei Dai ${ }^{3}$, Runtong Zhang ${ }^{1}$ (corresponding author) \\ ${ }^{1}$ Institute of Information Systems, School of Economics and Management, Beijing Jiaotong University (China) \\ ${ }^{2}$ School of Computer Science and Technology, Zhoukou Normal University (China) \\ ${ }^{3}$ School of Management and Information Systems, Victoria University (Australia) \\ liushenfir@163.com; liya@,zknu.edu.cn; wei.dai@vu.edu.au; rtzhang@,bjtu.edu.cn
}

Received September 2012

Accepted February 2013

\section{Abstract:}

Purpose: Improve work efficiency of logistics park department, and drive the economy of the park and its surrounding areas.

Design/methodology/approach: Analyze the information development situation and existent questions of current national logistics park, and design proper scheme to meet the demand of port logistics park.

Findings: Proposed an information construction implementation plan using technology of the Internet of things which can be applied to port logistics park. Designed a scheme for the park information construction and explained the system's implementation strategy and implementation steps.

Practical implications: The proposed construction program is particularly suitable for the northwest port logistics parks in China, and also has reference function to other logistics park construction.

Originality/value: Group the information construction of the logistics park into four levels, three types of users, and two requirements. The scheme is innovative and comprehensive, which can ensure the development of port logistics park.

Keywords: Logistics Park, Information Construction, the Internet of things, Frontier Port 


\section{Introduction}

In information age, the full development of logistics industry depends on its informatization. An important feature of modern logistics is the use of advanced information tools to manage logistics activities. Currently, numbers of experts and scholars at home and abroad have done in-depth research on the construction of logistics parks, especially on construction of information technology, and made a series of achievements. For example, Ketikidis, Koh, and Dimitriadis (2008) did research on the supply chain management application status of logistics information in southeast Europe, and proposed future development countermeasures. Hu (2004) carried on the analysis and design to the logistics information of modern postal industry. In view of the logistics development situation of our land port, and combine with the international logistics park in Pingxiang, Guangxi Province, Gui, Sun and Wang (2007) explored park informationization construction based on SOA architecture. These scientific results have important contributions to the promotion of China's logistics park information construction.

As the logistics development and location in different regions has its own particularity, existing research results are not universal. Especially in the vast territory of China's Xinjiang region, it borders with many countries, and has various types of ports. There are 17 national-level land ports. These ports have inherent geographical advantages, but many have not been supported by commensurate scientific research, and did not play its due role. This paper conducts the research on a national-level port in Xinjiang region as an example, applies some cutting-edge technologies to the design of the information system, and describes its practical implementation.

\section{Development status of China's logistics parks}

The logistics park (Fan \& Wang, 2005) is also known as logistics sites, which is a fully functioning place opened up by government from the overall interests of the city. It consists of one or more logistics enterprises concentrated on spatial layout, providing a certain category, scale and a high level of integrated logistics services, forming logistics rally point. The drive of logistics park informationization will effectively lead information process in various fields, and promote the socio-economic development of the whole region.

Construction of logistics parks in China has been developing rapidly recent years. Especially in the northwest, the vast territory provides more space for modern logistics park in the process of construction and development. What's more, it has innate advantage in port trade and regional economic development, which plays an important role on carrying out import and export trade, and stimulating regional economic growth. On the other hand, the country attaches importance to the construction of logistics information infrastructure environment. Eleventh Five-Year Plan clearly proposed that we should vigorously develop modern logistics 
industry and view logistics information as a key construction project. National preferential policies and counterpart assistance provide a strong external support and policy guarantee for the park construction. Under the support of governments of various levels, China's logistics information platform has made some progress with the development of logistics industry. A considerable part of enterprises have consummated their information system construction, and used modern management tools such as enterprise resource planning (ERP) and other technologies to improve production efficiency and management level.

In the process of information development of logistics parks, there also exposed many problems (Lu, 2009). One important issue is the low utilization rate of information technology. Many local governments are over-enthusiastic. The construction of information infrastructure is too blind and lack unified planning, causing the information infrastructure not compatible with certain business or logistics companies. Many parks were vacant without companies settled in. Another problem is that the IT and logistics talents tend not to keep up with the needs of modern park, many of the so-called information technologies are merely used to handle simple documents with computer, not networked. Logistics park did not establish a common data platform. The management departments and enterprises settled in the park each does things in his own way, forming "Information Island". It is difficult to unify management and share public information. Especially for small and medium-sized logistics enterprises, due to limited funding, resources, and so on, their information degree is low, and information technology applications in logistics are not sufficient. Manufacturing resource planning (MRP II ), enterprise resource planning (ERP), vendor managed inventory system (VMI), supply chain management (SCM), and other logistics software has not been widely applied. Although some circulation enterprises have implemented ERP, the success rate is less than $50 \%$.

\section{Design of port logistics park information system}

\subsection{Design goal}

Take the port logistics park in Xinjiang as an example, this park area possesses an important port for foreign trade in China. It is a crucial point joining the northern Xinjiang to Kazakhstan, Russia and other countries, playing an important role of connecting east and west. Considering the huge flow of importing and exporting goods and immigration clearance of visitors, we do analysis and design based on the specific needs, combining with the function of domestic and international logistics parks and logistics centers.

The overall goal of this logistics park information construction is to develop logistics industry in the park and improve soft environment for construction and investment. Through the development of logistics park, it can provide comprehensive logistics services for the running of the special economic port, construct the west important international logistics service 
centers and regional transit center, and promote the opening of the northern Xinjiang region as well as the trade with neighboring countries.

\subsection{Design principles}

Considering current development status and existing problems of the logistics park, following basic principles should be followed during the design of the port logistics information systems.

Firstly, practicality is the starting point. This logistics park is located in China's northwestern border, covering an extensive area of the county where suffers the inconvenience of traffic and poor exchange of information. Therefore, it is necessary to be based on the practical situation of the Park and strengthen the construction of integrated information service system to fundamentally change the inefficient service systems and backward trade means.

Secondly, use advanced technology to meet the requirements of "high starting point, high construction standard, and high management performance". We need to take into full account advanced technology roadmap and make most advantage of the northwest logistics park information construction, in order to raise technology to domestic advanced level. Among the existing advanced technology, fully tested and proven technology with a large number of success cases should be chosen.

Thirdly, security and reliability issues are related to the entire system, including the physical environment, information systems, data and resources. Adopt necessary security protection and redundancy design to make sure that the information is available, the data is accurate and complete, and the system is running reliably and healthily.

Fourthly, during the design process, use open and standardized technical infrastructure. Therefore, a standardized system with the ability of expanding can be constructed, and fine connectivity and extendibility of the system can be ensured.

Finally, information construction is a long-term task, and should advance constantly with the change of government functions and focus. In order to satisfy the unceasing need of development, extendibility is an important factor for the system design.

\subsection{Design proposal}

In accordance with the objectives and principles of design, the logistics park information construction can be grouped into four levels, three types of users, and two requirements. Four levels of the information system frame from low to high include data supporting platform, application system supporting platform, information application system, and the unification of information. Three types of users are consisting of government department personnel, companies or investors, and the public. Standardization and safeness are the two 
requirements. The basic framework of modern logistics park information system design is shown in figure 1.

\section{Four levels}

- The establishment of data supporting platform will effectively solve problems within and between departments such as data resources can 't be shared and non-standard data interface, so that to realize data scheduling, storage, exchange, management and other functions. Its core content is "data centralized storage management, provide share and exchange platform, provide public services and decision support services".

- From the physical view of deployment, application systems support platform play a connecting role between unstructured software such as underlying network devices, operating systems, databases and the upper-layer application software. It includes security framework, one-stop services framework, data integration framework and deployment framework.

- In the information application, each module has its own function. For example, remote service system can realize the unified monitoring and maintenance of system equipment through establishing a unified remote service platform; by integrating a variety of business, information and computer resources of port regulatory departments and local enterprises, electronic port system can realize data sharing, information flow and capital flow on the unified efficient computer physical platform. The electronic trading market uses the ASP+e-MarketPlace structure to establishment system, which can focus on resource management and application development.

- Establish a unified information portal system, which can provide users with an information display and publish window via interface integration. Portal framework follows the principle of unified exit and entrance. Through the unified portal services, it provides external application services at all levels and integrates internal business applications systems. Through the request to upper application service, scheduling the underlying business logic and its related business systems resources to complete the running of the event-driven information flow and data flow, thereby making the website manage login accounts of serviced subsystems uniformly. 


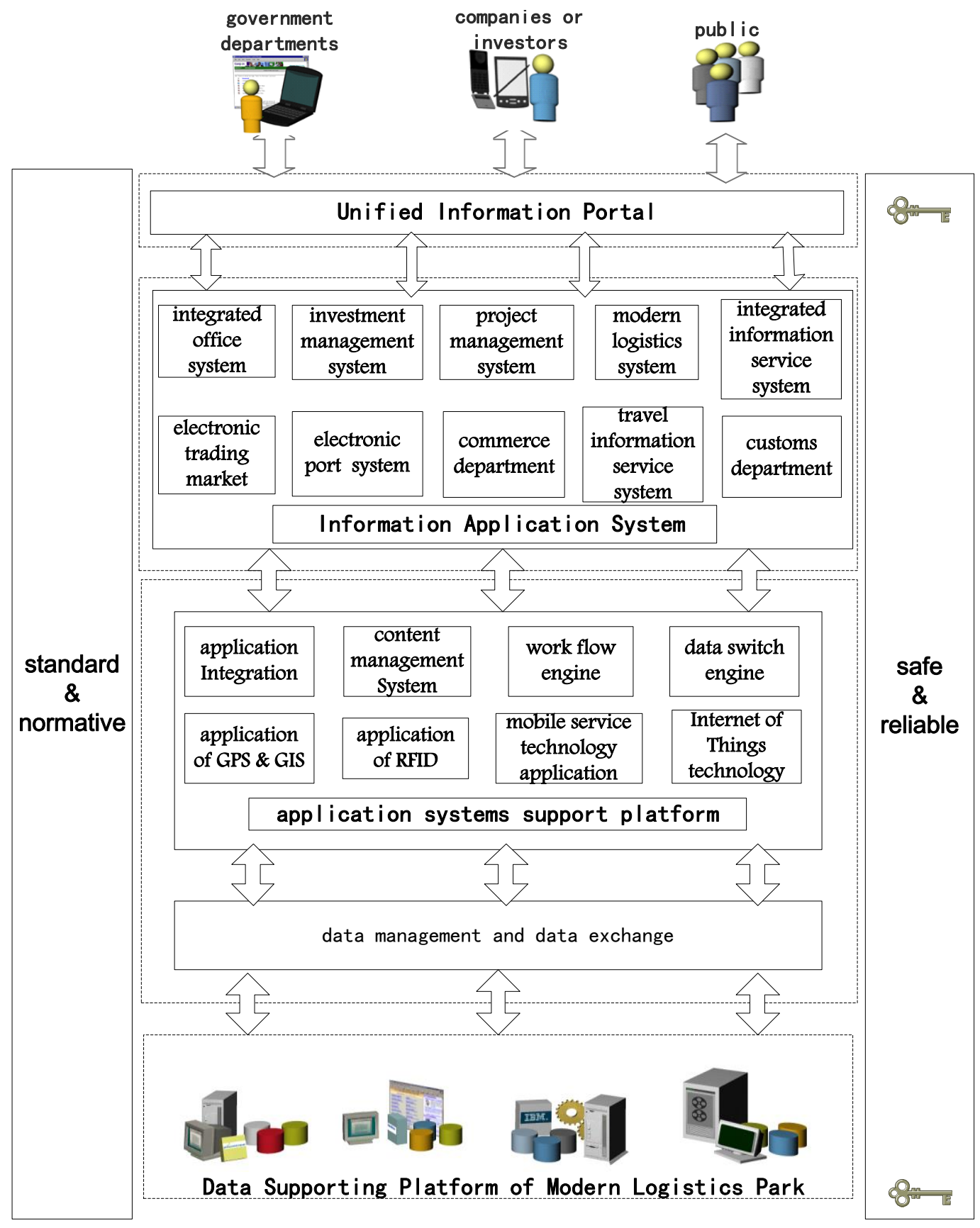

Figure 1. Framework diagram of modern logistics park information system

\section{Three types of users}

Users of modern logistics park information system under government support include government department personnel, companies or investors, and the public. For different categories of users should be set to different access to their system, which government department officers, mainly the logistics park's staff, are responsible for quarantine inspection of the items from or into the parks, managing enterprise data and maintenance of information system etc. Companies or investors concern about their own business system module or data, that is, data collection, processing and analysis, in order to make profitable 
decision using decision-making support function in the system; Public can access to the information system for e-transactions, queries such as logistics and so on.

\section{Two requirements}

The modern physical distribution garden area information system needs to satisfy two requests, namely the standardization of the design and the safeness and liableness. Standardization of the design means taking full advantage of open, standardized, fundamental and technical infrastructure, to establish a standardized system that are ensured to have good connectivity and the expandability, to meet the desire of the expanding size of the park and improving demands of development. Safeness and liableness refer that the systems not only are protected from external intrusion, to ensure data security within the system, but also requires fast response and less system failure.

\section{Realization of port logistics park information construction}

\subsection{Technology roadmap}

\section{Use the Internet of Things}

The Internet of Things (Zhao, Wang \& Gao, 2007) is on the basis of Internet, using RFID (Radio Frequency Identification) (Zhao, Wang \& Gao, 2008; Eleonora, Roberto \& Andrea, 2010) technology and EPC (Electronic Product Code) (Chen, Mitchell \& Lian, 2010) to form a physical Internet covering everything in the world. Due to the large scale of logistics parks and numbers of items, it is appropriate to use RFID technology to realize the real "one thing with one code", so that it can achieve park items interconnection, improve staff efficiency and minimize losses caused by artificial inventory errors.

\section{Integrated use of "3G" technology}

"3G" technology (Liu, Gao \& Ji, 2010) is global positioning system (GPS), geographic information systems (GIS) and Global System for Mobile Communications (GSM). GIS is for the traffic map in vehicle monitoring and dispatching system of the park, which can integrate the unique visualization and geographic analysis capabilities with the general database operations. Through the integrated use of GPS technology, it can constitute a commanding and dispatching powerful management network with combination of communications and positioning, so that achieve real-time running state monitoring and timely scheduling of vehicles. At the same time cooperating with the mobile service provider, it allows cargo owners or users to send short message to query and track vehicles, cargos and orders at any time, which lay the foundation for the establishment of intelligent transport systems. 


\section{Develop virtual logistics}

With communications network technology, virtual logistics (Dai, 2010) can integrate enterprise warehouses distributed in different areas into a large logistics support system, so that to realize sharing and optimized configuration of inter-enterprise logistics resources. It will build a virtual logistics organization, namely is supply chain information integration platform. Essentially it is a dynamic alliance of logistics enterprise in order to obtain the scale efficiency of the logistics field which is based on advanced information technology and linked by sharing supply chain information. It integrates logistics enterprises, carriers, warehouse operators, product suppliers and distributors together through the computer network technology to provide one-stop logistics services and improve the vulnerable position of individual companies in the logistics market.

\section{Build remote service management system}

Using the remote service, users can communicate instantly with service implementers. It can realize real-time artificial services between different regions and service for the local development with external information resources. It is necessary to build the unified remote service platform to realize unified monitoring of the system equipment, and use Internet/Intranet to achieve good communications between the external and internal systems.

\section{Establish an integrated port logistics information system}

To control the problem of "Information Island" of port agencies, establish public port data platform, centralizing data of the customs, inspection, quarantine station and other units to form a shared platform for information. On this basis, from a global perspective to provide the users lorry declaration, customs data query, enterprise business information publishing and other services which cover all aspects of import and export of enterprises. Customers settled in the logistics park use a unified information portal system. It is easy to management. At the same time, provide different access to system according to the permissions of different departments and different people, which can facilitate collaboration and optimization of business between the various departments, resulting in a summation effect to enhance the competitiveness of enterprises and regional comprehensive strength of the overall logistics park.

\subsection{Steps for construction}

Modern logistics park building is delivered to the information center of the operating company, and the information center is responsible to contact with the country electron government affairs, to complete the approval process of information construction as well as coordinate a variety of matters in the process of information system construction. 
About development style, it is better to choose software outsourcing, and authorize the software company to develop it. Leaders in county e-government department, management committee and information center should set up a leading group to support the development work. Information center set up a special project team responsible for specific work in the park information system development process, including the selection of the appropriate system developer, the time control of system construction, to supervise the construction process, as well as to contact with leaders and relevant departments to coordinate the problems.

During development, project team and Developer conduct research together to understand the specific needs and basic functions of the park system, and design implementation plan. After demanding is clear, organize sources, write code, build databases, debug and test run to complete system development work. The project team should guide the logistics park staff test the system to determine whether it meets the requirements. Once the test passes, convert the system and put it into operation. After the system is running, it is necessary to organize staff training, including system administrators and system users.

\section{Conclusion}

As a highly centralized logistics collection and distribution center, logistics park information construction is essential. Especially since the beginning of 21st century, Chinese logistics industry overall scale grows rapidly, logistics transport is a main business in the park. However, current sea-rail intermodal container transport has troubles such as complex cargo transfer and low artificial efficiency, which especially need the support of information technology and the Internet of Things. Therefore China should strive to make up the gap with the developed countries on e-commerce development level, improve the information and modernization of the logistics park, and improve the efficiency of business operations.

The proposed construction program in this paper is particularly suitable for the northwest port logistics park, and also has reference function to other logistics parks.

\section{References}

Chen, L., Mitchell, T., \& Lian, X. (2010). Development of foundation models for Internet of Things. Frontiers of Computer Science in China, 4, 376-385. http://dx.doi.org/10.1007/s11704010-0385-8

Dai, Y. (2010). The construction and management of virtual logistics enterprise alliance. Beijing, ON: China Logistics Publishing House. 
Eleonora, B., Roberto, M., \& Andrea, V. (2010). The impact of RFID and EPC network on the bullwhip effect in the Italian FMCG supply chain. International Journal of Production Economics, 124, 425.

Fan, D.C, \& Wang, T.J. (2005). The analysis on the status quo and existing problem of logistic park in our country. Logistics SCI Tech, 28, 1-4.

Gui, S.P., Sun, W.W., \& Wang, D.C. (2007). Building of information platform of inland port logistics distribution based on SOA. Hoisting and Conveying Machinery, 3, 33-35.

Hu, X.D. (2004). Design of integrated platform for collaborative production of telecommunication industry based on e-stamps. Computer Integrated Manufacturing Systems, $10,1149-1153$.

Ketikidis, P.H., Koh, S.C.L., \& Dimitriadis, N. (2008). The use of information systems for logistics and supply chain management in south east Europe. Current Status and Future Direction, 36, 592-599.

Liu, Y., Gao, X., \& Ji, L.L. (2010). The research of 3G-based CRM system. Chinese Journal of Scientific Instrument, 24, 376-385.

Lu, Y.F. (2009). The existing circumstance and enlightenment for Chinese logistics informationization. Journal of Wuhan Institute of Technology, 31, 41-43.

Zhao, Y.N., Wang, W.Q., \& Gao, L. (2007). Software design for a contactless smart card reader in logistic park. Transactions of Beijing Institute of Technology, 27, 961-964, 992.

Zhao, Y.N., Wang, W.Q., \& Gao, L. (2008). Study on the data transmission project of RFID card in logistics park. Transactions of Beijing Institute of Technology, 28, 27-31.

Journal of Industrial Engineering and Management, 2013 (www.jiem.org)

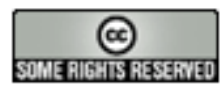

El artículo está con Reconocimiento-NoComercial 3.0 de Creative Commons. Puede copiarlo, distribuirlo y comunicarlo públicamente siempre que cite a su autor y a Intangible Capital. No lo utilice para fines comerciales. La licencia completa se puede consultar en http://creativecommons.org/licenses/by-nc/3.0/es/ 